\title{
STRATEGI PENGEMBANGAN HOMESTAY DI DESA WISATA BONGAN, TABANAN-BALI
}

\author{
Dinar Sukma Pramesti \\ Email: dinar.pramesti@pib.ac.id \\ POLITEKNIK INTERNASIONAL BALI
}

\begin{abstract}
The purpose of this research is to analyze the potential and strategy of homestay development in the Bongan tourist village, TabananBali. The method used was descriptive qualitative. The data were gained from observation, interview, documentation, and literature study. The analysis technique was SWOT analysis (Strengths, Weaknesses, Opportunities, Threats). The theory of the nine criteria for homestay according to the ASEAN Homestay standard (2016) is the reference of this study.

The results show that four strategies can be used to develop a homestay in the tourist village of Bongan: 1) strategy of displaying activities carried out by the local community; 2) strategy promotion regarding the existence of homestay in Bongan village; 3) strategy homestay development with attention to traditional Balinese architecture, safety, comfort and cleanliness; 4) strategy to create a homestay management group in the tourist village of Bongan. The results of the research are expected to be able to help the development of the tourist village of Bongan and increase community income.
\end{abstract}

Keywords: Strategy, Development, Homestay

\section{ABSTRAK}

Desa Wisata Bongan, terletak di Kabupaten Tabanan. Sebagai desa wisata, Bongan harus memiliki fasilitas penunjang pariwisata seperti sarana akomodasi wisata. Tujuan penelitian ini yaitu menganalisis potensi dan strategi pengembangan homestay di Desa Wisata Bongan, TabananBali. Metode yang digunakan yaitu deskriptif kualitatif. Metode pengumpulan data yang digunakan adalah observasi, wawancara, studi dokumentasi dan kepustakaan. Teknik analisis menggunakan analisis SWOT (Strengths, Weaknesses, Opportunities, Threats). Teori yang digunakan sebagai acuan dalam penelitian ini yaitu teori Sembilan kriteria homestay menurut ASEAN Homestay standard (2016).

Hasil penelitian menunjukkan bahwa terdapat empat strategi yang dapat digunakan untuk mengembangkan homestay di Desa Wisata Bongan 
yaitu: 1) strategi menampilkan aktivitas yang dilakukan oleh masyarakat setempat; 2) strategi promosi tentang keberadaan homestay di desa Bongan; 3) strategi pengembangan homestay dengan memperhatikan arsitektur tradisional Bali, keamanan, kenyamanan dan kebersihan; 4) strategi membuat kelompok pengelola homestay di Desa Wisata Bongan. Hasil penelitian ini diharapkan mampu membantu dalam upaya pengembangan Desa Wisata Bongan dan meningkatkan pendapatan masyarakat.

Kata Kunci: Strategi, Pengembangan, Homestay.

\section{Pendahuluan}

Desa Wisata Bongan adalah salah satu desa di Kabupaten Tabanan Bali. Desa Wisata Bongan memiliki luas 4,45 $\mathrm{km}^{2}$. Desa Wisata Bongan memiliki 9 Banjar Adat, 11 Banjar Dinas, dan 2 Desa Adat (Kecamatan Tabanan dalam Angka, 2019). Desa Wisata Bongan ditetapkan sebagai desa wisata oleh Dinas Pariwisata Kabupaten Tabanan berdasarkan SK Nomor 180/457/03/HK\&HAM/2018. Desa Wisata Bongan memiliki tiga potensi yang diandalkan yaitu daya tarik wisata situs Kebo Iwa dan Pura Puseh Bedha, daya tarik wisata air terjun Grembengan, serta daya tarik wisata Penangkaran Jalak Bali.

Sebagai desa wisata, Bongan harus memiliki berbagai fasilitas penunjang yang memudahkan para pengunjung dalam melakukan kegiatan wisata seperti sarana transportasi, telekomunikasi, kesehatan, dan akomodasi. Berkaitan dengan sarana akomodasi, Desa Wisata Bongan dapat menyediakan sarana penginapan berupa pondok wisata (homestay) sehingga wisatawan dapat tinggal bersama penduduk setempat dan merasakan suasana pedesaan Bongan.

Homestay merupakan akomodasi yang cocok dikembangkan di desa wisata, karena memiliki harga yang terjangkau dan sekaligus dapat meningkatkan tingkat pendapatan masyarakat desa (Kemenpar 2015). Homestay juga akan mampu membantu pengembangan Desa Wisata 
Bongan karena dapat menarik wisatawan untuk meluangkan waktu lebih lama dan berinteraksi dengan masayarakat lokal.

Berdasarkan hasil wawancara dengan Sukarta, selaku kepala Desa Bongan (2020), saat ini Desa Wisata Bongan belum memiliki fasilitas akomodasi wisata berupa homestay. Suarsa (2020), selaku ketua Desa Wisata Bongan menambahkan bahwa masyarakat Bongan memiliki beberapa kamar kosong di rumahnya, sayangnya masyarakat belum memahami cara memulai memanfaatkannya sebagai homestay. Berdasarkan latar belakang tersebut, maka dilakukan suatu penelitian terkait strategi pengembangan homestay di Desa Wisata Bongan, TabananBali. Penelitian ini diharapkan mampu membantu Desa Wisata Bongan dalam upaya mengembangkan akomodasi wisata berupa homestay

\section{Kriteria dan Persyaratan Homestay}

Homestay merupakan rumah atau kamar masyarakat yang ditumpangi atau disewa oleh wisatawan (Chairunisa, 2015). Homestay adalah kegiatan wisata alternatif sehingga wisatawan akan tinggal bersama keluarga atau pemilik rumah di area rumah yang sama, dan akan merasakan pengalaman hidup sehari-hari dari keluarga tersebut dan masyarakat lokalnya (ASEAN Homestay Standard, 2016). Aspek utama yang ditawarkan oleh homestay selain sarana akomodasi, adalah pengalaman hidup sebagai orang lokal dengan merasakan secara langsung nilai-nilai budaya yang dijalankan oleh masyarakat lokal.

Homestay menurut ASEAN Homestay Standard (2016), memiliki sembilan kriteria yaitu:

1) Terdapat penyedia homestay

2) Terdapat fasilitas akomodasi seperti bangunan, kamar tidur, dan kamar mandi atau toilet 
3) Adanya aktivitas yang dilakukan oleh masyarakat setempat yang menjadi daya tarik wisata.

4) Terdapat manajemen atau sebuah organisasi pengelola

5) Lokasi (aksesibilitas) yang mudah diakses dengan berbagai model transportasi darat, laut, udara. Perlu juga ada papan penunjuk arah untuk menuntun wisatawan mencapai homestay

6) Memperhatikan tingkat higienis dan kebersihan dengan memperhatikan tiga hal yaitu rumah (bangunan) tempat tamu menginap beserta fasilitasnya, kebersihan lingkungan sekitar homestay dan tingkat kebersihan proses pembuatan makanan bagi tamu yang menginap

7) Menyediakan fasilitas keselamatan dan keamanan

8) Adanya aktivitas promosi

9) Menerapkan prinsip berkelanjutan seperti economic sustainable, environmental sustainability dan sociocultural sustainability sehingga kegiatan pariwisata di daerah homestay menjadi berkelanjutan dalam jangka waktu Panjang kedepannya.

\section{Metode}

Penelitian ini menggunakan pendekatan desktiptif kualitatif. Dalam pendekatan deskriptif kualitatif, data yang telah diperoleh selanjutnya dianalisis, diuraikan, dijelaskan dan digambarkan secara sistematis dan objektif. Lokasi penelitian berada di Desa Wisata Bongan yang terdapat di wilayah Kecamatan Tabanan, Kabupaten Tabanan. Jarak Kabupaten Tabanan dari pusat kota Denpasar adalah sekitar $23 \mathrm{~km}$ sedangkan dari arah bandara Ngurah Rai sekitar $34 \mathrm{~km}$. Instrumen penelitian adalah peneliti sendiri yang dilengkapi dengan alat-alat bantu seperti pedoman wawancara, alat tulis dan alat dokumentasi. 
Metode pengumpulan data yang digunakan adalah observasi, wawancara, studi dokumentasi dan kepustakaan. Metode observasi dilakukan dengan melakukan pengamatan, disertai pencatatan terhadap keadaan maupun perilaku objek sasaran (Fatoni, 2011). Observasi dalam penelitian ini dilakukan dengan pengamatan langsung di Desa Wisata Bongan. Wawancara adalah teknik pengumpulan data melalui proses tanya jawab lisan dari yang mewawancarai dan jawaban diberikan oleh yang diwawancarai. Informan yang diwawancarai yaitu Kepala Desa, Sekretaris Desa, Ketua Desa Wisata, Ketua Pokdarwis Dewi Manis Bongan. Studi dokumentasi dan kepustakaan dilakukan dengan cara mencari dan mengumpulkan informasi dari dokumen, buku/artikel. Analisis menggunakan analisis SWOT yang terdiri dari Strengths (kekuatan) dan Weaknesses (kelemahan) lingkungan internal serta Opportunities (peluang) dan Threats (ancaman) lingkungan eksternal (Rangkuti, 2014).

\section{Pembahasan}

Dalam pembahasan dibahas dua hal yaitu analisis potensi pengembangan homestay di Desa Wisata Bongan dan strategi pengembangan homestay di Desa Wisata Bongan

4.1 Analisis Potensi Pengembangan homestay di Desa Wisata Bongan

Dalam analisis potensi, dijabarkan mengenai kekuatan, kelemahan, peluang dan tantangan dalam upaya pengembangan homestay di Desa Wisata Bongan

A. Kekuatan

1) Desa Wisata Bongan memiliki aksesibilitas yang baik dan masyarakat memiliki kamar kosong yang dapat dijadikan sebagai homestay

Desa Wisata Bongan terletak di Kabupaten Tabanan, kabupaten Tabanan dapat dijangkau melalui jalur darat, udara dan laut. Kabupaten Tabanan berada dekat dengan pusat Kota Denpasar yaitu 
sekitar 23 km, dari Pelabuhan Gilimanuk berjarak 106 km, sedangkan dari arah bandara Ngurah Rai sekitar $34 \mathrm{~km}$. Lokasi Desa Wisata Bongan yang berada di kabupaten Tabanan cukup mendukung pengembangan homestay di Desa Wisata Bongan. Apalagi saat ini Desa Wisata Bongan sedang gencar dalam mengembangkan pariwisata.

Suarsa (wawancara, 4 Oktober 2020), selaku ketua Desa Wisata Bongan mengungkapkan bahwa masyarakat Bongan ingin memiliki usaha yang mendukung pariwisata di Desa Wisata Bongan yaitu dengan menyediakan jasa akomodasi berupa homestay. Keinginan tersebut didasari karena rata-rata masyarakat Desa Wisata Bongan memiliki kamar tidur yang tidak digunakan dan dapat dimanfaatkan sebagai homestay. Pernyataan tersebut juga didukung oleh Makir (wawancara, 4 Oktober 2020), selaku ketua Pokdarwis Dewi Manis Bongan. Menurutnya masyarakat memiliki kamar kosong karena berkurangnya jumlah anggota keluarga karena meninggal maupun telah menetap di kota Denpasar karena alasan pekerjaan dan sedang menempuh Pendidikan. Kamar kosong yang akan dijadikan homestay telah dilengkapi dengan kamar mandi dengan fasilitas bath up dan closet. Area tersebut terdapat di satu bangunan bale dangin atau bale meten dan terpisah dari bangunan tempat tinggal pemilik rumah namun masih dalam satu pekarangan, sehingga tidak mengganggu privasi wisatawan yang menginap.

2) Memiliki Pokdarwis Dewi Manis yang mengatur jalannya kegiatan pariwisata

Berdasarkan hasil wawancara dengan Makir (wawancara, 4 Oktober 2020), selaku ketua Pokdarwis Dewi Manis Bongan, Desa Wisata Bongan memiliki kelembagaan yang terdiri dari kelompok- 
kelompok sadar wisata yang ada di Desa Wisata Bongan yang tergabung dalam Pokdarwis Dewi Manis. Pokdarwis Dewi Manis bertugas mengatur jalannya kegiatan pariwisata di Desa Wisata Bongan serta melakukan kerjasama dengan pemerintah daerah, perguruan tinggi maupun pihak swasta yang akan membantu masyarakat dalam pengembangan pariwisata yang salah satunya adalah pengembangan usaha akomodasi berupa homestay.

B. Kelemahan

1) Kamar masyarakat Bongan yang akan dijadikan homestay belum memenuhi standar wisata

Berdasarkan hasil observasi di lapangan terlihat bahwa kamar yang dimiliki oleh masyarakat Desa Wisata Bongan yang akan dijadikan homestay belum sesuai kriteria homestay menurut ASEAN Homestay Standard (2016) karena belum memperhatikan tingkat higienis, kebersihan, keselamatan dan keamanan. Kamar yang dimiliki karena tidak dihuni sehingga agak berdebu, belum dilengkapi dengan air conditioner, dan belum dilengkapi dengan fasilitas keselamatan dan keamanan.

2) Masyarakat belum memiliki pengetahuan tentang pengelolaan homestay.

Sukarta (wawancara, 4 Oktober 2020) selaku Kepala Desa Wisata Bongan mengungkapkan bahwa masyarakat Desa Wisata Bongan mayoritas adalah petani. Pengetahuan yang dimiliki dibidang pariwisata sangat minim. Masyarakat Bongan ingin memiliki homestay, sudah ada modal untuk itu, tetapi belum paham cara memulai usaha homestay. Suarsa (wawancara, 4 Oktober 2020), selaku ketua Desa Wisata Bongan menambahkan perlu ada satu, dua orang yang menjadi pelopor di Desa Wisata Bongan dalam memulai dan menjalankan usaha homestay. Menurutnya jika satu, dua orang telah 
berhasil mengembangkan homestay, maka otomatis yang lainnya akan mengikuti.

C. Peluang

1) Mampu memberikan kesejahteraan bagi masyarakat Desa Wisata Bongan

Usaha homestay disinyalir mampu meningkatkan perekonomian masyarakat Desa Wisata Bongan baik bagi pengelola sendiri maupun masyarakat sekitar. Masyarakat sekitar diuntungkan dengan menjadi tenaga kerja homestay maupun membuka unit usaha lainnya. Adanya homestay juga akan mampu menggerakkan unit usaha lainnya seperti restoran, laundry, money changer. Dengan meningkatnya taraf ekonomi masyarakat Bongan, akan diikuti dengan kenaikan tingkat kesejahteraan masyarakat Bongan.

2) Dapat menjadi sarana pengenalan budaya, kuliner khas bongan.

Rumah masyarakat Desa Wisata Bongan merupakan rumah dengan arsitektur tradisional Bali. Dijadikannya bangunan/kamar di area rumah masyarakat Desa Wisata Bongan dapat menjadi sarana pengenalan konsep rumah tradisional Bali. Aktivitas sehari-hari yang dilakukan oleh pemilik rumah seperti sembahyang, menghaturkan banten/canang, menggunakan pakaian adat maupun memberikan suguhan makan makanan tradisional juga dapat menjadi sarana pengenalan budaya masyarakat Bongan termasuk kuliner khas Bongan. Makir (wawancara, 4 Oktober 2020) selaku ketua Pokdarwis Dewi Manis mengungkapkan bahwa Desa Wisata Bongan saat ini sedang mengembangkan produk unggulan Desa yaitu Gonda. Gonda merupakan sayuran yang banyak terdapat di Desa Wisata Bongan. Gonda dapat diolah menjadi plecing Gonda, keripik Gonda, maupun produk Teh khas Desa Wisata Bongan yang diberi nama teh Gobo 
(Gonda Bongan). Teh Gobo dapat dijadikan welcome drink bagi wisatawan yang menginap di homestay sehingga keberadaan homestay dapat menjadi salah satu cara memperkenalkan produk khas Bongan.

D. Ancaman

1) Persaingan antar sesama homestay/usaha akomodasi lainnya

Dengan semakin banyaknya masyarakat Desa Wisata Bongan yang mengembangkan homestay, Suarsa (wawancara, 4 Oktober 2020), selaku ketua Desa Wisata Bongan berharap agar tidak terjadi persaingan antar sesama pemilik homestay, melainkan dapat saling mendukung misalnya jika ada satu homestay yang sudah full, namun masih ada wisatwan yang memesan, dapat diarahkan ke homestay milik masyarakat Bongan lainnya. Sehingga untuk mencegah adanya persaingan antar pemilik homestay di Bongan, pihaknya akan membentuk kumpulan pengusaha homestay Desa Wisata Bongan.

2) Rusaknya lingkungan, pengaruh budaya luar, ketergantungan yang berlebihan pada pariwisata, naiknya harga tanah/lahan

Adanya pengembangan homestay juga dikhawatirkan akan membuat masyarakat Bongan yang awalnya petani, berubah profesi atau menggantungkan hidupnya di dunia pariwisata. Hal tersebut tentunya akan mengakibatkan berkurang atau hilangnya sawah di Desa Wisata Bongan. Hal lainnya yang dikhawatirkan akan terjadi adalah masuknya budaya asing yang merusak budaya asli masyarakat Bongan. 


\subsection{Strategi Pengembangan Homestay di Desa Wisata Bongan}

\begin{tabular}{|c|c|c|}
\hline Eksternal & $\begin{array}{l}\text { Kekuatan (Strengths) } \\
\text { - Memiliki aksesibiltas yang } \\
\text { baik dan tersedia kamar } \\
\text { yang dapat dijadikan } \\
\text { sebagai homestay } \\
\text { - Pokdarwis Dewi Manis } \\
\text { membantu pengembangan } \\
\text { usaha homestay }\end{array}$ & $\begin{array}{l}\text { Kelemahan (Weaknesses) } \\
\text { - Kamar yang dimiliki } \\
\text { belum memenuhi standar } \\
\text { - belum memiliki } \\
\text { pengetahuan pengelolaan } \\
\text { homestay }\end{array}$ \\
\hline $\begin{array}{l}\text { Peluang } \\
\text { (Opportunities) } \\
\text { - mampu memberikan } \\
\text { kesejahteraan bagi } \\
\text { masyarakat desa } \\
\text { - dapat menjadi sarana } \\
\text { pengenalan budaya, } \\
\text { kuliner khas bongan }\end{array}$ & \begin{tabular}{l}
\multicolumn{1}{c}{ Strategi SO } \\
Menampilkan aktivitas yang \\
dilakukan oleh masyarakat \\
setempat
\end{tabular} & \begin{tabular}{l}
\multicolumn{1}{c}{ Strategi WO } \\
Promosi tentang keberadaan \\
homestay di desa Bongan
\end{tabular} \\
\hline $\begin{array}{l}\text { Ancaman (Threats) } \\
\text { - persaingan antar } \\
\text { sesama homestay/usaha } \\
\text { akomodasi lainnya } \\
\text { - } \text { rusaknya lingkungan, } \\
\text { pengaruh budaya luar, } \\
\text { ketergantungan yang } \\
\text { berlebihan pada } \\
\text { pariwisata, naiknya } \\
\text { harga tanah/lahan }\end{array}$ & \begin{tabular}{l}
\multicolumn{1}{c}{ Srategi ST } \\
Pengembangan homestay \\
dengan memperhatikan \\
arsitektur tradisional Bali, \\
keamanan, kenyamanan dan \\
kebersihan.
\end{tabular} & $\begin{array}{l}\quad \text { Strategi WT } \\
\text { Membuat kelompok } \\
\text { pengelola homestay di Desa } \\
\text { Wisata Bongan }\end{array}$ \\
\hline
\end{tabular}

Berdasarkan mastriks SWOT, strategi yang dapat dilakukan untuk pengembangan homestay di Desa Wisata Bongan yaitu sebagai berikut:

1) Strategi Strengths-Opportunities (SO):

Strategi SO yaitu strategi yang menggunakan kekuatan yang dimiliki untuk memanfaatkan peluang yang mungkin didapatkan. Adapun strategi yang dilakukan yaitu menampilkan aktivitas yang dilakukan oleh masyarakat setempat. Strategi ini mengacu pada Sembilan kriteria pengembangan homestay yang ditetapkan oleh ASEAN Homestay Strandard (2016), yaitu terdapat aktivitas yang dilakukan oleh masyarakat setempat yang dapat menjadi daya tarik wisata. Aktivitas tersebut dapat berupa tari-tarian, gamelan maupun pertunjukan alat musik lainnya, penyelenggaraan upacara maupun aktivitas lainnya yang dapat dilakukan di sekitaran homestay seperti 
bersepeda, jogging, yoga, dan megunjungi daya tarik wisata yang ada di Desa Wisata Bongan. Aktivitas tersebut bisa ditawarkan kepada wisatawan dalam bentuk paket wisata.

Seluruh aktivitas yang ada harus menunjukkan identitas keaslian dari Desa Wisata Bongan, baik dari nilai-nilai budaya, tata cara hidup, kerajinan tangan dan makanan lokal khas Desa Wisata Bongan. Wisatawan yang datang untuk meyewa homestay juga bisa diberikan sambutan sehingga dapat memberikan kesempatan wisatawan untuk mengenal warga masyarakat secara lebih dekat dan memberikan first impression yang baik kepada tamu,

2) Strategi Weaknesses-Opportunities (WO):

Strategi WO yaitu mengatasi kelemahan yang dimiliki dengan memanfaatkan peluang. Adapun strategi yang dapat dilakukan yaitu strategi promosi tentang keberadaan homestay di Desa Wisata Bongan yang dilakukan oleh pengelola homestay melalui media sosial, website maupun menjalin kerjasama dengan operator perjalanan baik online maupun offline.

3) Strategi Strengths- Threats (ST):

Strategi ST menggunakan kekuatan dalam menghadapi ancaman. Adapaun strategi yang dapat dilakukan yaitu strategi penggunaan arsitektur tradisional Bali sebagai bentuk identitas homestay. Masyarakat Desa Wisata Bongan adalah masyarakat lokal yang beragama Hindu. Rumah yang dimiliki adalah rumah tradisional masyarakat Bali yang berlandaskan filosofi ajaran agama Hindu seperti penggunaan konsep Tri Hita Karana, Tri Angga, Sanga Mandala. Pengembangan homestay di Desa Wisata Bongan sebaiknya tetap mempertahankan penggunaan arsitektur tradisional agar homestay terlihat lebih menyatu dengan lingkungan sekitar, sehingga atmosfir membaur dengan keseharian keluarga pemilik rumah. 
Perlu juga pihak homestay menyediakan rasa keamanan dan kenyamanan seperti memiliki kemampuan memberikan pertolongan pertama pada hal-hal yang sifatnya darurat. Pengelola homestay wajib memberikan rasa aman kepada tamu dengan memasang CCTV atau security yang bertugas menjaga keamanan homestay. Adanya SOP (Standard Operating Procedure) yang juga dijelaskan kepada tamu yang menginap dalam bentuk hal-hal apa saja yang boleh dan tidak diperbolehkan dilakukan selama menginap di homestay tersebut juga dapat memberikan rasa aman dan nyaman. Pemilik homestay juga harus senantiasa menjaga kebersihan homestay. Kamar dilengkapi dengan tempat sampah, agar wisatawan juga dapat menjaga kebersihan kamar dan AC.

4) Strategi Weaknesses-Threats (WT):

Strategi WT dilakukan dengan meminimalisir kelemahan dan menghindari ancaman. Adapun strategi yang dapat dilakukan yaitu membuat kelompok pengelola homestay di Desa Wisata Bongan dan diperlukan satu orang ketua kelompok yang mampu bersikap adil untuk mendistribusikan wisatawan yang datang ke Desa Wisata Bongan.

\section{Simpulan dan Rekomendasi}

Hasil penelitian menunjukkan bahwa terdapat empat strategi yang dapat digunakan untuk mengembangkan homestay di Desa Wisata Bongan yaitu: 1) strategi menampilkan aktivitas yang dilakukan oleh masyarakat setempat; 2) strategi promosi tentang keberadaan homestay di Desa Wisata Bongan; 3) strategi pengembangan homestay dengan memperhatikan arsitektur tradisional Bali, keamanan, kenyamanan dan kebersihan; 4) strategi membuat kelompok pengelola homestay di Desa Wisata Bongan. 
Adapun rekomendasi yang dapat diberikan untuk mengelola dan mengembangkan homestay di Desa Wisata Bongan antara lain dengan menyelenggarakan ataupun mengikuti sosialisasi Pedoman atau standar Pengelolaan Homestay. Selain itu juga dapat dilakukan pelatihan tentang homestay dan pengelolaannya secara rutin dengan mengundang pihak pemerintah, swasta, akademisi/institusi. Hal tersebut dimaksudkan agar pengelola homestay di Desa Wisata Bongan dapat mengelola homestay sesuai standar dan membuat wisatawan merasa nyaman tinggal lebih lama di Desa Wisata Bongan. Pemilik homestay di Desa Wisata Bongan hendaknya aktif mengikuti pelatihan-pelatihan yang diberikan.

\section{Daftar Pustaka}

ASEAN. (2016). ASEAN Homestay Standard. Jakarta: The ASEAN Secretariat

BPS Kabupaten Tabanan. (2019). Kecamatan Tabanan Dalam Angka. BPS Kabupaten Tabanan.

Chairunisa, M. (2015). Ini alasan "homestay" lebih menarik dibanding hotel. Retrieved February 25, 2018, from http://travel.kompas.com/read/2015/09/14/092600127/Ini.Alasan. Homestay.Lebih Menarik Dibanding.Hotel

Damanik, Fitharia Khairina. (2014). Homestay sebagai Usaha Pengembangan Desa Wisata Kandri. Jurnal Teknik PWK, 3, 10601071

Fatoni, Abdurrahman. (2011). Metodologi Penelitian dan Teknik Penyususna Skripsi. Jakarta: Rineka Cipta

Kemenpar. (2019). Pengembangan Desa Wisata Berbasis Pendampingan Melalui Perguruan Tinggi. Jakarta: Kemenpar

Rangkuti, Freddy. (2014). Analisis SWOT: Teknik Membedah Kasus Bisnis. Jakarta. PT Gramedia Pustaka Utama

\section{Profil Penulis}

Dinar Sukma Pramesti, S.T., M.T. adalah Dosen prodi DIV Manajemen Perhotelan di Politeknik Internasional Bali. Lahir di Denpasar 12 September 1988. Menamatkan Sarjana Teknik Arsitektur di Universitas Udayana pada tahun 2010. Melanjutkan Pendidikan Magister di bidang arsitektur dengan mengambil konsentrasi Arsitektur Kajian Lingkungan Binaan Etnik di Pascasarjana Universitas Udayana yang diselesaikan tahun 2013. 
Dinar Sukma Pramesti

108 JOURNEY Volume 3 Nomor 1, Desember 2020 